\title{
Expandable Right Ventricular-to-Pulmonary Artery Conduit: An Animal Study
}

\author{
YOUNES BOUDJEMLINE, FRANÇOIS LABORDE, EMMANUELLE PINEAU, ALIX MOLLET, SYLVIA ABADIR, \\ NICOLAS BORENSTEIN, LUC BEHR, AND PHILIPP BONHOEFFER
}

\begin{abstract}
Pediatric Cardiology [Y.B., A.M., S.A.], EMIU 0016, Pr Lafon [Y.B.], Necker Hospital for Sick Children, 75015 Paris, France; IMM Research [F.L., N.B., L.B.], Montsouris Institute, 75014 Paris, France; Cardiothoracic Unit [E.P.], Marie Lannelongue Surgical Center, 92350 Le Plessis Robinson, France; Cardiothoracic Unit [P.B.], Great Ormond Street Hospital, London WC1B 3JH,
\end{abstract}

United Kingdom

\begin{abstract}
This study was performed to assess a new vascular stent graft as an expandable valved conduit for right ventricular outflow tract (RVOT) reconstruction in sheep. Conduits were constructed by sewing an 18-mm valved conduit inside a stent. Crimped to $16 \mathrm{~mm}$, they were implanted either under or without extracorporeal circulation in seven (group A) and in five (group B) sheep, respectively. Six weeks and 3 mo after their insertion, conduits were dilated intraluminally. A valved stent was implanted percutaneously into conduits before they were killed. Two animals from group A recovered normally, whereas five animals had a complicated postoperative course. In group B, one died acutely due to kinking of the conduit. Balloon dilatations were performed in all surviving animals. First dilatations had a slight impact on valvular function in all animals but one, whereas second dilatations led to significant PR in all. Transcatheter valve implantation was performed successfully. When animals were killed, no bleeding was found around the surgically implanted device. In conclusion, we designed a biologic valved conduit for RVOT reconstruction that can be dilated sequentially to follow animal growth. This new device can have tremendous applications in children with congenital heart diseases involving the RVOT. (Pediatr Res 59: 773-777, 2006)
\end{abstract}

$\mathrm{P}$ rosthetic conduits with and without valves have been used surgically to re-establish continuity between the right ventricle (RV) and the pulmonary artery (PA) bifurcation in congenital heart defects involving the RVOT (e.g. truncus arteriosus, tetralogy of Fallot, double-outlet RV and pulmonary stenosis, d-transposition of the great arteries with ventricular septal defect and pulmonary stenosis) (1). Despite some limitations, homografts remain a widely used option to restore the continuity of the RVOT (2-4). Mismatch between demand and supply for homografts makes their availability a limiting factor, in particular when small sizes are considered. Moreover, small homografts used in neonates and infants require frequent replacement $(3,5-7)$. Over the past four decades, a large number of valved xenografts, classified according to the type of valve incorporated and the structure sup-

Received October 27, 2005; accepted February 1, 2006

Correspondence: Younes Boudjemline, M.D., Ph.D., Service de Cardiologie Pédiatrique, Hôpital Necker-Enfants-Malades, 149, rue de Sèvres, 75015 Paris cedex, France; e-mail: younes.boudjemline@nck.ap-hop-paris.fr.

Financial support for these studies was provided by the British Heart Foundation (London, UK), AREMCAR (Paris, France), and "Fondation de l'Avenir" (Paris, France).

DOI: $10.1203 / 01 . p d r .0000219396 .34610 .4 a$ porting this valve, have been developed and implanted in the pulmonary position $(8-14)$. None have demonstrated superiority over homografts, but due to their unlimited availability, they have become the preferentially used graft in many surgical centers. Moreover, some recent reports $(6,15)$ suggest that durability as well as the type of implanted conduit chosen may be a less critical issue in younger children because, in this age group, conduits are outgrown before they degenerate.

Transcatheter techniques (e.g. balloon dilatation, bare stent placement, valved stent insertion) have been proposed to delay the need for reoperation (16-20). However, these techniques have limited efficacy in children with small conduits because of the inability to expand the conduit over its nominal size. Therefore, the availability of a "growing" conduit would significantly improve the management of these patients. Based on our experience of valve insertion through a transcatheter technique, we have used a valved stent to fashion a dilatable conduit for surgical implantation allowing dilatation according to growth up to a diameter permitting transcatheter valve placement. Animal implantation, balloon dilatations of this conduit, and transcatheter valve insertion are described.

\section{METHODS}

Preparation of the dilatable valved conduit. The dilatable valved conduit was first constructed by sewing an $18-\mathrm{mm}$ valved bovine jugular vein conduit (Contegra, Medtronic Inc., Minneapolis, $\mathrm{MN}$ ) inside a vascular stent (CP stent, Numed Inc.) The wall of the Contegra was not reduced as performed for transcatheter insertion (20). The vascular stent was shorter than the one used for transcatheter pulmonary valve insertion, with a length of $15 \mathrm{~mm}$ when inflated to $18 \mathrm{~mm}$ (Fig. 1).

Animal preparation. Twelve sheep (INRA, Paris, France) were included in the present study and divided in two groups according to the technique used to insert the conduit. Seven animals had the conduits inserted using extracorporeal circulation (ECC) (group A). In the remaining five animals, conduits were implanted without ECC (group B). All animals received medical care according to the European guidelines for laboratory animal care (21). The study was approved by the Ethical Committee of Montsouris Hospital (Paris, France).

Abbreviations: ECC, extracorporeal circulation; MPA, main pulmonary artery; PA, pulmonary artery; PR, pulmonary regurgitation; RA, right atrium; $\mathbf{R V}$, right ventricle; RVOT, right ventricular outflow tract 


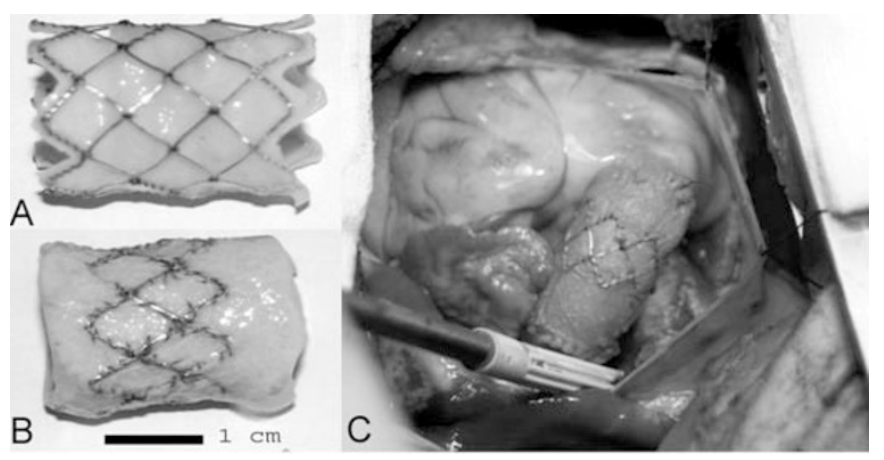

Figure 1. Valved stent available for transcatheter implantation $(A)$ and the dilatable conduit assessed in the present study $(B)$. (C) Surgical view showing dilatable conduit after its placement under extracorporeal circulation.

Insertion of the dilatable valved conduit. Surgery was performed under general anesthesia via left thoracotomy. Anesthesia was induced with ketamine hydrochloride (300-500 mg i.v.) and was maintained with inhaled drugs (halothane $0.5-2 \%$ ). Arterial pressure was monitored continuously by an ear arterial line. Electrocardiography and heart rate were documented continuously.

In animals from group A (ECC group), grafts were implanted in the main pulmonary artery (MPA) with a beating heart and without myocardial protection. Access to cardiopulmonary bypass was gained via the right femoral artery and the right atrium (RA) with a cannula introduced from the right jugular vein. Under full cardiopulmonary bypass flow, the MPA was crossclamped below its bifurcation and opened transversally $1 \mathrm{~cm}$ above the pulmonary annulus. The native valve was excised by resecting each leaflet. The annulus was preserved. Conduits were fashioned in length according to the anatomy of each animal. The prepared conduits were crimped to $16 \mathrm{~mm}$ in diameter and inserted to replace the excised MPA with 4-0 Prolene running suture. This diameter was chosen to avoid important downsizing of the RVOT diameter. The animals were weaned off ECC and cannulas removed.

In animals from group B (non-ECC group), conduits were inserted as previously reported by Valente et al. (22). Briefly, the anterior MPA was partially clamped using a vascular clamp. This part was incised, and the conduit was sutured using a running suture. Proximal anastomosis to the RV was created using the same technique by partial clamping of the anterior infundibular portion of the RV. After insertion, conduits were de-aired, vascular clamps released, and native RVOT ligated. After placement of chest drains, the wounds were closed in layers.

In all animals from both groups, hemodynamic (i.e. RA, RV, and PA pressures) and angiographic (RV and PA angiograms) studies were performed to assess valvular function as well as pressure gradients across conduits and the anastomosis. The animals were extubated after the evaluation and the anesthetic drugs were discontinued. Drains were removed the next morning. Postoperative medical treatment consisted of antibiotics for $48 \mathrm{~h}$, analgesia, and anticoagulation (i.e. low molecular weight heparin for $2 \mathrm{~d}$ and aspirin 100 $\mathrm{mg}$ i.v. once daily throughout the protocol).

Follow-up of animals, transcatheter dilatation of conduits and valve insertion. For long-term observation, sheep were transferred to a farm. They were reassessed at $6 \mathrm{wk}$ and $3 \mathrm{mo}$ or sooner if complications became apparent. Re-evaluation consisted of a cardiac catheterization with angiographic and hemodynamic assessments. Cardiac catheterizations were performed under general anesthesia with the aim of dilating the surgically inserted conduit. A $7 \mathrm{~F}$ introducer sheath was inserted in the right jugular vein. Using a right Judkins coronary catheter (Cordis) advanced in the PA, an exchange 0.035-in. wire was placed in the distal PA. Eighteen-millimeter and $20-\mathrm{mm}$ balloon catheters (Tyshak II, Numed Inc.) at $6 \mathrm{wk}$ and $3 \mathrm{mo}$, respectively, were advanced over the previously inserted wire and subsequently inflated to dilate the surgically inserted conduit. Before and after dilatation, hemodynamic and angiographic data were acquired to assess the function of the implanted valve. A 22-mm valved stent was implanted through a transcatheter technique into the previously placed dilatable conduit with a device and technique described previously (20) if one of the following criteria was present: 1) complete follow-up of 3 mo even if valvular function was not impaired and/or 2) if at any point during the follow-up, a significant pulmonary regurgitation (PR) was apparent before or after dilatation. The severity of PR was graded using the following system extrapolated from grading severity of aortic regurgitation (23): $0=$ no PR, $1+=$ contrast enters but does not fill the RV, $2+=$ contrast fills the RV but not as densely as the PA, and $3+=$ contrast fills the $\mathrm{RV}$ as densely as the PA. Angiograms were considered adequate to grade PR severity if the catheter was positioned in the distal main PA or a branch PA with the catheter ports well away from the pulmonary valve. There was no catheter recoil into the RV with contrast injection, and the MPA was filled back to the pulmonary valve.

Graft retrieval. All grafts were explanted following the insertion of the valved stent. The heart and the lungs were retrieved together in one block. All hearts were dissected and inspected macroscopically. The pulmonary vascular tree was examined to determine the position of each device (i.e. valved stent, conduit) in relation to the adjacent structures. Anastomotic sites were studied. Devices were then harvested and rinsed with a section of the infundibular portion and pulmonary arteries. All grafts were inspected and the competence of each valve grossly tested by injecting liquid into the graft. Valved stents were removed carefully and valves from conduits inspected and tested similarly.

\section{RESULTS}

Surgical placement of the dilatable conduit: Animals from group A (ECC). The dilatable valved conduit was implanted surgically in all included animals after a mean extracorporeal circulation time of $65 \mathrm{~min}$ (range, 55-85) (Fig. 1). Acute hemodynamic assessment showed a functioning valve in all animals, and a maximum transprosthetic pressure gradient of $10 \mathrm{~mm} \mathrm{Hg}$ (range, 2-22). Two animals had a simple postoperative course and survived. Five animals had a complicated postoperative course and needed slow weaning off ECC with postoperative inotropic support. Because we hypothesized that even with a small transprosthetic gradient, hemodynamically unstable animals could have a substantial obstruction, a balloon dilatation with a larger balloon was performed in two of these five animals to reduce the afterload of the failing RV. In one of these two, a rupture of the proximal anastomotic suture occurred, leading to fatal thoracic bleeding. Of these five animals, only one recovered.

Survivors were followed according to the protocol $(n=$ 3/7) (Table 1).

Surgical placement of the dilatable conduit: Animals from group $B$ (non-ECC). Four of five animals had uneventful outcome and completed the study as planned $(n=4)$ (Table 2). In one animal, proximal anastomosis was narrowed, leading to high RV pressure and subsequent acute RV failure. In this animal, we reopened the native RVOT to decrease the RV pressure, but, after transient recovery, the animal died suddenly while the chest was being closed. Acute hemodynamic assessment showed a functioning valve in all animals and a maximum transprosthetic gradient of $14 \mathrm{~mm} \mathrm{Hg}$ (range, 2-30) (Fig. 2).

Balloon dilatation of the conduits $(\boldsymbol{n}=7)$. The first and second dilatations were performed after a mean time of 1.6 (range, 0.7-3.9) and 2.9 mo (range, 0.8-5.5) after the surgical insertion of the conduit, respectively. In the surviving animals from group A, systolic RV pressure dropped from 44 to 33 $\mathrm{mm} \mathrm{Hg}$ after the first dilatation and from 35 to $30 \mathrm{~mm} \mathrm{Hg}$ after the second dilatation. The diameter increased to 17.6 and 19.8 $\mathrm{mm}$, respectively. In animals from group B, the mean systolic RV pressure did not change significantly after successive balloon inflations $(31 \mathrm{~mm} \mathrm{Hg}$ after surgical insertion, and, respectively, 30 and $32 \mathrm{~mm} \mathrm{Hg}$ after first and second dilatations) since most of the gradient was found in the area of the ventricular anastomosis. PR was absent to slight in all animals before dilatation except in one in which it was moderate. In this animal, dilatation with the $18-\mathrm{mm}$ balloon catheter wors- 
Table 1. Hemodynamic data of animals with RV-PA conduit inserted using extracorporeal circulation (group A)

\begin{tabular}{|c|c|c|c|c|c|c|}
\hline Animal & $\begin{array}{c}\text { RVP prior } \\
\text { (S/D/end-D) } \\
(\mathrm{mm} \mathrm{Hg})\end{array}$ & $\begin{array}{l}\text { PAP prior } \\
(\mathrm{S} / \mathrm{D} / \mathrm{M}) \\
(\mathrm{mm} \mathrm{Hg})\end{array}$ & $\begin{array}{l}\text { RVP post } \\
\text { (S/D/end-D) } \\
(\mathrm{mm} \mathrm{Hg})\end{array}$ & $\begin{array}{l}\text { PAP post } \\
(\mathrm{S} / \mathrm{D} / \mathrm{M}) \\
(\mathrm{mm} \mathrm{Hg})\end{array}$ & $\begin{array}{l}\mathrm{mRV} \text { to } \mathrm{PA} \\
\text { gradient post } \\
\quad(\mathrm{mm} \mathrm{Hg})\end{array}$ & Outcome \\
\hline 1 & $27 / 0 / 6$ & $30 / 17 / 22$ & $36 / 0 / 8$ & $28 / 15 / 20$ & 8 & Alive \\
\hline 3 & $25 / 0 / 5$ & $19 / 12 / 16$ & $42 / 0 / 10$ & $27 / 12 / 19$ & 15 & Alive \\
\hline 4 & $18 / 0 / 6$ & $17 / 11 / 13$ & $30 / 0 / 12$ & $18 / 8 / 14$ & 12 & Alive \\
\hline 5 & $20 / 0 / 6$ & $20 / 10 / 12$ & $30 / 0 / 12$ & $20 / 13 / 17$ & 10 & Dead \\
\hline Mean & $25.3 / 0 / 5.7$ & $24.4 / 12.6 / 16.6$ & $33.3 / 0 / 10.4$ & $23.1 / 12.7 / 18$ & 10.1 & \\
\hline $\mathrm{p}$ & NA & NA & $0.01 / \mathrm{NA} / 0.02$ & NS/NS/NS & & \\
\hline
\end{tabular}

$\mathrm{RVP}$, right ventricular pressure; PAP, pulmonary artery pressure; $\mathrm{mRV}$ to PA, systolic right ventricular to pulmonary artery; S/D/end-D, systolic/diastolic/ end-diastolic; S/D/M, systolic/diastolic/mean; p, comparison between pre- and post-measurements; NA, not applicable.

Table 2. Hemodynamic data after RV-PA conduit inserted without extracorporeal circulation (group B)

\begin{tabular}{|c|c|c|c|c|c|c|}
\hline Animal & $\begin{array}{l}\text { RVP prior } \\
\text { (S/D/end-D) } \\
(\mathrm{mm} \mathrm{Hg})\end{array}$ & $\begin{array}{l}\text { PAP prior } \\
(\mathrm{S} / \mathrm{D} / \mathrm{M}) \\
(\mathrm{mm} \mathrm{Hg})\end{array}$ & $\begin{array}{l}\text { RVP post } \\
\text { (S/D/end-D) } \\
(\mathrm{mm} \mathrm{Hg})\end{array}$ & $\begin{array}{l}\text { PAP post } \\
(\mathrm{S} / \mathrm{D} / \mathrm{M}) \\
(\mathrm{mm} \mathrm{Hg})\end{array}$ & $\begin{array}{c}\mathrm{mRV} \text { to } \mathrm{PA} \\
\text { gradient pre/post } \\
(\mathrm{mm} \mathrm{Hg})\end{array}$ & Outcome \\
\hline 1 & $23 / 0 / 6$ & $21 / 10 / 16$ & $35 / 0 / 8$ & $23 / 10 / 16$ & $2 / 12$ & Alive \\
\hline 3 & $21 / 0 / 6$ & $21 / 13 / 16$ & $52 / 0 / 10$ & $22 / 17 / 19$ & $0 / 30$ & Dead \\
\hline 4 & $20 / 0 / 6$ & $19 / 12 / 15$ & $33 / 0 / 7$ & $15 / 8 / 12$ & $1 / 18$ & Alive \\
\hline 5 & $19 / 0 / 5$ & $17 / 9 / 11$ & $28 / 0 / 7$ & $19 / 1316$ & $2 / 9$ & Alive \\
\hline
\end{tabular}

RVP, right ventricular pressure; PAP, pulmonary artery pressure; $\mathrm{mRV}$ to PA, systolic right ventricular to pulmonary artery; S/D/end-D, systolic/diastolic/ end-diastolic; S/D/M, systolic/diastolic/mean; p, comparison between pre- and post-measurements; NA, not applicable.

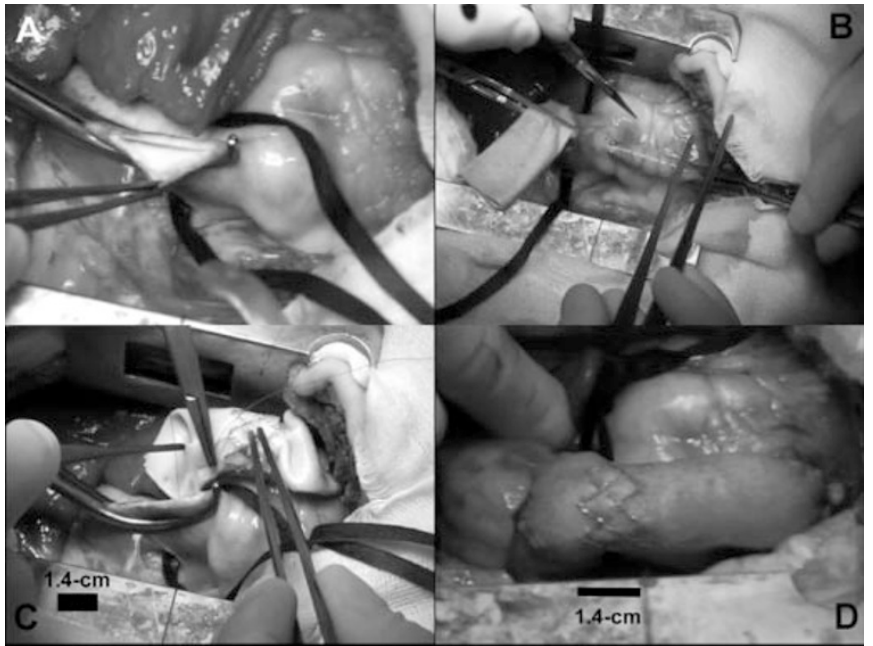

Figure 2. Surgical views of conduits inserted without cardiopulmonary bypass. (A) View showing partial cross-clamping of the MPA. The MPA is shown open before suturing of the dilatable conduit. $(B)$ View showing partial cross-clamping of the infundibulum of the RV before its opening. The distal anastomosis has already been performed. $(C)$ View showing the distal anastomosis being performed. $(D)$ Final aspect of the dilatable conduit and ligation of the native MPA below the distal anastomosis.

ened the insufficiency from moderate to severe. Elsewhere, the first dilatation had only a slight impact on valvular function (from grade $0-1+$ to grade $1-2+$ ). Dilatation with the $20-\mathrm{mm}$ balloon catheters led to mild to severe regurgitation in all animals (Fig. 3).

Transcatheter valve insertion. Transcatheter valve implantation was attempted and successful in seven out of seven surviving animals (Fig. 4). All implanted valves were func-

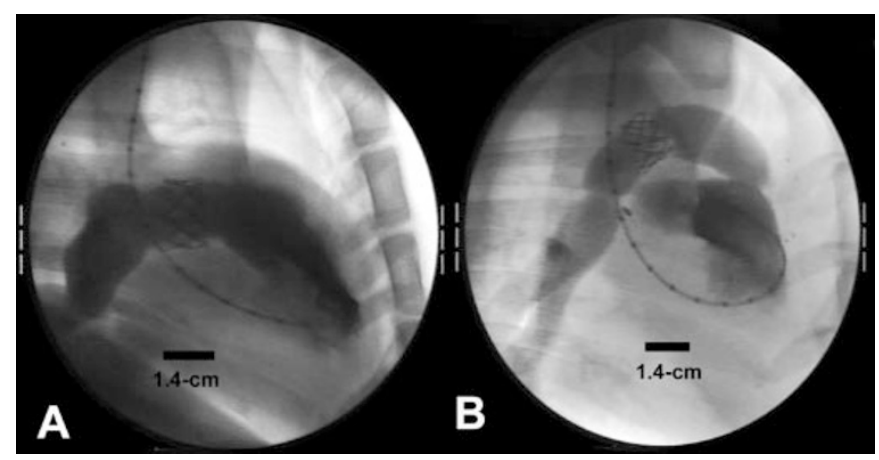

Figure 3. Right ventricular angiograms showing a dilatable conduit at the 3 -mo follow-up in an animal with conduit in native $(A)$ and in extra-anatomic (B) positions.

tioning angiographically. No early migration occurred in any animals. Diastolic pressure increased slightly from 9 to $13 \mathrm{~mm}$ $\mathrm{Hg}$ reflecting the excellent valvular function. This valvular implantation was performed prematurely at $6 \mathrm{wk}$ in one animal from group A because of the occurrence of significant PR after dilatation with the $18-\mathrm{mm}$ balloon. At autopsy, the valve of the conduit was severely calcified with incomplete coaptation of the leaflets.

Autopsy and graft retrieval. Five animals died acutely (four from group A and one from group B). Macroscopic examination showed well-positioned conduits without any surgical problem in four animals from group A. In one animal from group B, the ventricular anastomosis was severely stenosed due to a short ventricular opening and kinking of the conduit with a too horizontal orientation. Valves were all competent. In one animal from group $\mathrm{A}$, distal suture was torn (due to 


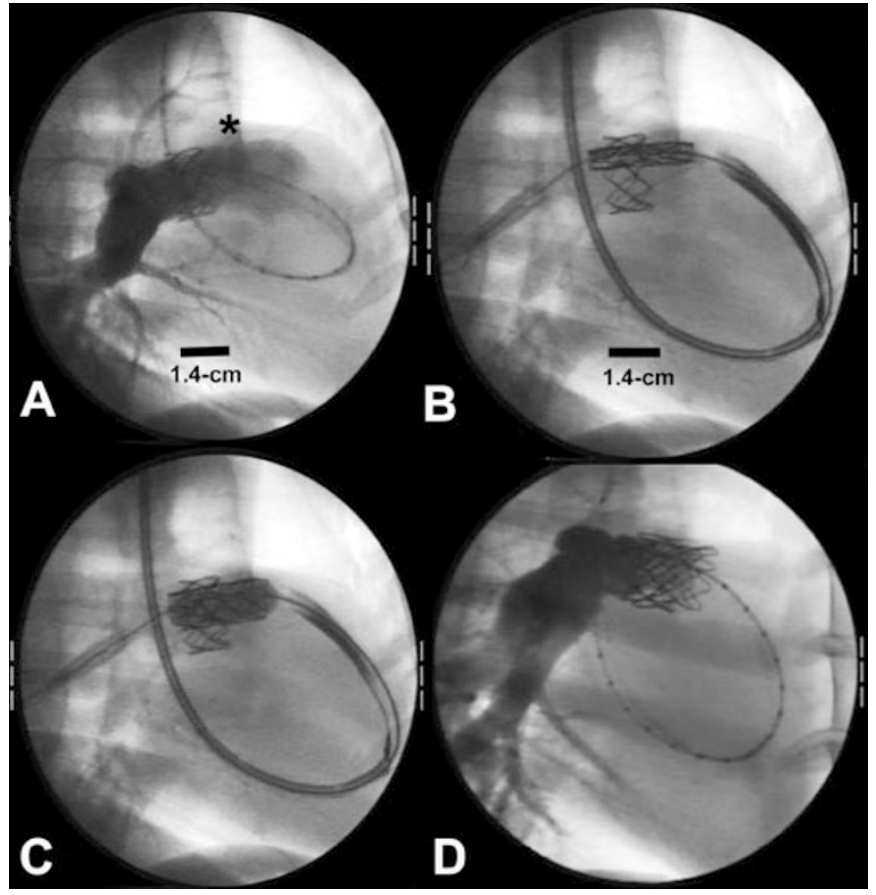

Figure 4. Angiograms showing the conduit after dilatation with a $20-\mathrm{mm}$ balloon catheter $(A)$ and percutaneous valve insertion at various steps of insertion $(B-D)$. (A) PA angiogram showing significant pulmonary insufficiency (*) with contrast dye expanding below the level of the valve. $(B)$ The valved stent is easily placed using the dilatable conduit as a radio-opaque marker. (C) Once in position, the balloons are subsequently inflated. (D) Pulmonary angiogram obtained after valve insertion. Following valved stent insertion, note the disappearance of pulmonary insufficiency as demonstrated by the absence of contrast dye below the level of the stent $(A, D)$.

early balloon dilatation) and abundant thoracic bleeding was present. In all animals killed at the end of the protocol, no bleeding was found around the surgically implanted devices. All conduits were heavily surrounded by a fibrotic tissue (Fig. 5). Valved stents were in perfect position in the area of the surgically placed conduits. Valves from conduits were free of calcific process except in one animal (as described in the previous section).

\section{DISCUSSION}

During the past $10 \mathrm{y}$, improvements in the preparation and conservation have led to a significant increase of the life span of prosthetic conduits. However, despite increased longevity, conduits are quickly outgrown, especially by pediatric patients. As a result, such patients require frequent surgical replacement of RV-to-PA conduits. Percutaneous stenting of conduits has recently been established to relieve stenosis and delay the surgical replacement of the conduit (17-19). However, this technique is limited by its inability to expand the conduit over its nominal diameter because it is supported by nondilatable material. This is particularly true in neonates and small children in whom conduits are usually replaced because of outgrowth rather than valvular degeneration $(6,15)$. In our experience, placing stents in patients with small conduits has no or little impact on the life span of the conduits (data not shown). Two recently introduced conduits, Shelhigh (Shelhigh Inc., Union) and Contegra conduits (Medtronic Inc.) are

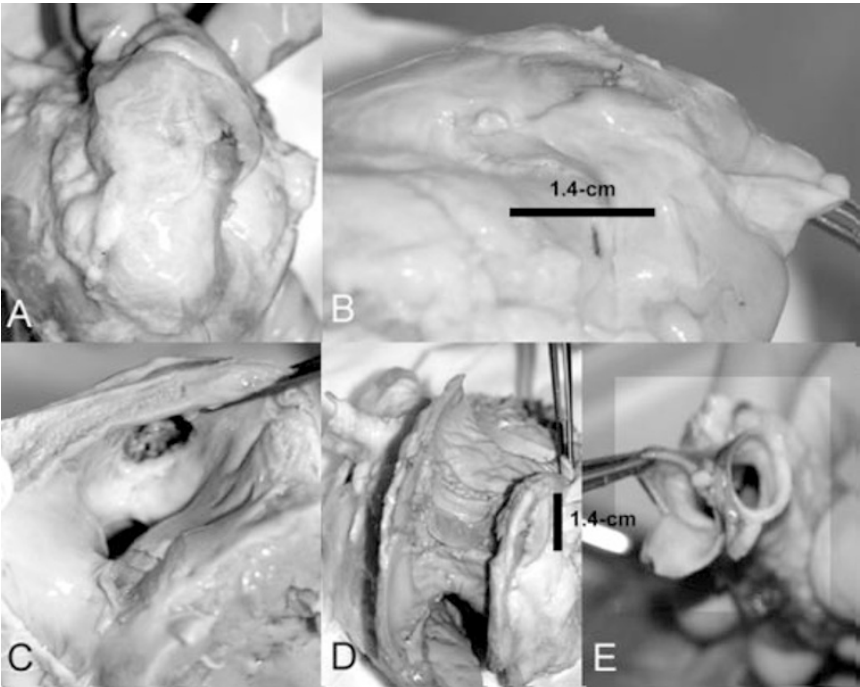

Figure 5. Autopsy views showing extra-anatomic conduit embedded in fibrotic tissue ( $A$, en face view; $B$, lateral view). (C) View from the RV showing the native (inferior) and the neopulmonary orifices (superior). $(D)$ The conduit has been opened from ventricular (inferior) to pulmonary (superior) anastomosis. (E) Frontal view of the pulmonary bifurcation showing no pathologic stenosis.

not supported by Dacron, making stent implantation theoretically possible. No data are presently available to support the fact that stents could be implanted and subsequently balloon dilated in Contegra and Shelhigh conduits. We therefore developed a surgically implanted conduit that can be dilated throughout life up to a diameter of $22 \mathrm{~mm}$ in which a valved stent can be implanted by a transcatheter technique. A biologic valve was harvested from a bovine jugular vein and mounted unprepared into a short vascular stent. This stent acted as a support to avoid kinking and aneurysmal dilatation of the conduit and allowed further dilatations using transcatheter balloon catheters. Moreover, in vitro, this valve is made of three leaflets with redundant tissue that allows for overdilatation without repercussion on valvular function. For example, an $18-\mathrm{mm}$ valve can be dilated to $22 \mathrm{~mm}$ without creating significant regurgitation, making this valve particularly interesting. We hypothesized that the same would apply in vivo.

Twelve animals were included in the present study. We initially inserted the conduits using extracorporeal circulation but faced a high early mortality $(4 / 7,57 \%)$. To distinguish mortality related to the device itself from the one secondary to cardiopulmonary bypass, subsequent conduits were inserted without ECC in an extra-anatomic position. Using this approach, only one animal out of five died (mortality rate = $20 \%$ ). Excluding animals which died due to technical problems (i.e., cardiopulmonary bypass and conduit kinking), we were able to sequentially dilate the implanted conduits with a small loss of valvular function in six out of seven. In one animal, we had to prematurely insert a valve after the first dilatation with the $18-\mathrm{mm}$ balloon. At autopsy, valve leaflets from this conduit were calcified and their movements were restricted with inadequate coaptation after the first dilatation. Dilatation with a 20-mm balloon catheter led to significant PR in all animals. As a comparison, implantation of a bare stent, 
in a situation of conduit stenosis, leads to free PR since it applies the valve against the wall of the conduit. We were able to implant a valve through a transcatheter technique in all living animals, restoring the valvular function in all. Apart from the loss of valvular competency, no complication resulted from sequential conduit dilatations that were performed electively at $6 \mathrm{wk}$ and $3 \mathrm{mo}$. A disruption of the proximal anastomosis occurred in one animal leading to death due to uncontrolled thoracic bleeding. This severe complication was encountered with a conduit dilated just after its insertion.

Limitations to the study. Due to unavailability of small circuit for extracorporeal circulation, we were unable to include small animals with a high capability to grow. This leads to the inability to create rapid and significant gradient over the conduit despite a long follow-up. However, we demonstrated the possibility of dilating the conduit from 16 to $22 \mathrm{~mm}$. From a clinical point of view, to be valuable, the goal should be to develop a conduit dilatable from a neonatal (8 to $12 \mathrm{~mm}$ ) to an adult size (up to $20 \mathrm{~mm}$ ). We speculate that these conduits could be dilated from 12 to $22 \mathrm{~mm}$ in diameter, but experimental demonstration remains to be made. Similarly, possible compression of adjacent structures (in particular, coronary arteries) remains to be investigated before implantation of these conduits in children. Because with time the conduit can become embedded in fibrotic tissue, its dilatability could be impaired or reduced. In the present study, we did not observe this problem despite conduits fully covered with fibrotic tissue at autopsy. Even if we did not encounter this drawback, this is likely to occur after a long period of time. To answer this question, longer follow-up is required. Even if completely covered, these conduits should be dilatable with the use of high-pressure balloons. Alternatively, we can imagine dilating those conduits electively every 6 to 12 mo before any appearance of conduit stenosis to avoid these kinds of drawbacks.

\section{CONCLUSION}

The life span of right ventricular-to-PA conduits is limited due to valvular degeneration or conduit outgrowth. We report the development and application of a valved conduit allowing repeated dilatations following patient growth up to a diameter that permits nonsurgical implantation of a pulmonary valve. This approach potentially reduces the expected number of surgical interventions required to replace malfunctioning or outgrowing conduits and could therefore have an important impact on the management of right-sided congenital heart disease. Moreover, the use of such grafts can be envisioned for other cardiovascular or vascular locations.

Acknowledgments. The authors thank Numed Inc. and Medtronic Inc. for their technical support.

\section{REFERENCES}

1. Downing TP, Danielson GK, Schaff HV, Puga FJ, Edwards WD, Driscoll DJ 1985 Replacement of obstructed right ventricular-pulmonary arterial valved conduits with nonvalved conduits in children. Circulation 72:II84-II87

2. Homann M, Haehnel JC, Mendler N, Paek SU, Holper K, Meisner H, Lange R 2000 Reconstruction of the RVOT with valved biological conduits: 25 years experience with allografts and xenografts. Eur J Cardiothorac Surg 17:624-630

3. Tweddell JS, Pelech AN, Frommelt PC, Mussatto KA, Wyman JD, Fedderly RT, Berger S, Frommelt MA, Lewis DA, Friedberg DZ, Thomas JP Jr, Sachdeva R, Litwin SB 2000 Factors affecting longevity of homograft valves used in right ventricular outflow tract reconstruction for congenital heart disease. Circulation 102:130-135

4. Koirala B, Merklinger SL, Van Arsdell GS, McCrindle BW, Borger MA, Caldarone CA, Coles JG, Williams WG 2002 Extending the usable size range of homografts in the pulmonary circulation: outcome of bicuspid homografts. Ann Thorac Surg 73:866-870

5. Cleveland DC, Williams WG, Razzouk AJ, Trusler GA, Rebeyka IM, Duffy L, Kan Z, Coles JG, Freedom RM 1992 Failure of cryopreserved homograft valved conduits in the pulmonary circulation. Circulation 86:II150-153

6. Forbess JM, Shah AS, St Louis JD, Jaggers JJ, Ungerleider RM 2001 Cryopreserved homografts in the pulmonary position: determinants of durability. Ann Thorac Surg 71:54-60

7. Welters MJ, Oei FB, Witvliet MD, Vaessen LM, Cromme-Dijkhuis AH, Bogers AJ, Weimar W, Claas FH 2002 A broad and strong humoral immune response to donor HLA after implantation of cryopreserved human heart valve allografts. Hum Immunol 63:1019-1025

8. Chanda J, Kuribayashi R, Abe T 1997 New generation valved conduit: an experimental study. J Thorac Cardiovasc Surg 114:218-223

9. Ichikawa Y, Noishiki Y, Kosuge T, Yamamoto K, Kondo J, Matsumoto A 1997 Use of a bovine jugular vein graft with natural valve for right ventricular outflow tract reconstruction: a one-year animal study. J Thorac Cardiovasc Surg 114:224-233

10. Herijgers P, Ozaki S, Verbeken E, Van Lommel A, Meuris B, Lesaffre E, Daenen W, Flameng W 2002 Valved jugular vein segments for right ventricular outflow tract reconstruction in young sheep. J Thorac Cardiovasc Surg 124:798-805

11. Carrel T, Berdat P, Pavlovic M, Pfammatter JP 2002 The bovine jugular vein: a totally integrated valved conduit to repair the right ventricular outflow. J Heart Valve Dis 11:552-556

12. Bové T, Demanet H, Wauthy P, Goldstein JP, Dessy H, Viart P, Deville A, Deuvaert FE 2002 Early results of valved bovine jugular vein conduit versus bicuspid homograft for right ventricular outflow tract reconstruction. Ann Thorac Surg 74:536-541

13. Kanter KR, Fyfe DA, Mahle WT, Forbess JM, Kirshbom PM 2003 Results with the Freestyle porcine aortic root for right ventricular outflow tract reconstruction in children. Ann Thorac Surg 76:1889-1895

14. Hartz RS, Deleon SY, Lane J, Dorotan J, Joyce J, Urbina E, Ross-Ascuitto N, Ascuitto R 2003 Medtronic freestyle valves in right ventricular outflow tract reconstruction. Ann Thorac Surg 76:1896-1900

15. Forbess JM 2004 Conduit selection for right ventricular outflow tract reconstruction: contemporary options and outcomes. Semin Thorac Cardiovasc Surg Pediatr Card Surg Annu 7:115-124

16. Ovaert C, Caldarone CA, McCrindle BW, Nykanen D, Freedom RM, Coles JG, Williams WG, Benson LN 1999 Endovascular stent implantation for the management of postoperative right ventricular outflow tract obstruction: clinical efficacy. J Thorac Cardiovasc Surg 118:886-893

17. O'Laughlin MP, Slack MC, Grifka RG, Perry SB, Lock JE, Mullins CE 1993 Implantation and intermediate-term follow-up of stents in congenital heart disease. Circulation 88:605-614

18. Hosking MC, Benson LN, Nakanishi T, Burrows PE, Williams WG, Freedom RM 1992 Intravascular stent prosthesis for right ventricular outflow obstruction. J Am Coll Cardiol 20:373-380

19. Bonhoeffer P, Boudjemline Y, Saliba Z, Hausse AO, Aggoun Y, Bonnet D, Sidi D, Kachaner J 2000 Transcatheter implantation of a bovine valve in pulmonary position: a lamb study. Circulation 102:813-16

20. Boudjemline Y, Agnoletti G, Piechaud JF, Iserin L, Vouhe P, Bonnet D, Sidi D, Bonhoeffer P 2003 Remplacement valvulaire pulmonaire par voie percutanée: vers une modification de la prothèse. Arch Mal Coeur Vaiss 96:461-466

21. Convention européenne sur la protection des animaux vertébrés utilisés à des fins expérimentales ou à d'autres fins scientifiques. $1999 \mathrm{~J}$ Officiel Communautes Eur L222:29-37

22. Valente M, Laborde F, Thiene G, Milano A, Talenti E, Gallix P 1992 Glutaraldehyde-fixed bovine iliac veins used as bioprosthetic conduits: an experimental animal study. J Card Surg 7:156-162

23. Grossman W 1986 Profiles in valvular heart disease. In: Grossman W, ed. Cardiac Catheterization and Angiography. 3rd ed. Lea \& Febiger, Philadelphia, pp 359-381 